\title{
IoT and Machine Learning Based Stem Borer Pest Prediction
}

\author{
Rana Muhammad Nadeem ${ }^{1}$, Arfan Jaffar ${ }^{2}$ and Rana Muhammad Saleem ${ }^{3, *}$ \\ ${ }^{1}$ Govt. Post Graduate College Burewala, 61010, Pakistan \\ ${ }^{2}$ The Superior University Lahore, 54000, Pakistan \\ ${ }^{3}$ The University of Agriculture Faisalabad Sub Campus, Burewala, 61010, Pakistan \\ *Corresponding Author: Rana Muhammad Saleem. Email: rana.m.saleem@uaf.edu.pk \\ Received: 03 June 2021; Accepted: 11 July 2021
}

\begin{abstract}
Global climatic changes have severe impacts on agricultural productivity. Enhanced pest attacks on crops are one of the major impacts on sustainable developments in agriculture to come up with the needs of the ever-increasing human population. Early warning of a pest attack is important for Integrated Pest Management (IPM) activities to be effective. Early warning of pest attacks is also important for judicious use of pesticides for efficient use of resources for minimal impacts on the environment. Sugarcane is the major cash crop and is also severely affected by different types of pests. This study proposed stem borer attack prediction on sugarcane crops by directly sensed environment conditions from the crop field using the Internet of Things (IoT). Data-driven machine learning decisions are made to predict the pest population from directly sensed crop field temperature, humidity, and rainfall conditions. Directly sensed environment conditions and the data-driven decision by the Naïve Bays classification approach help to accurately predict the occurrence of a pest attack above or below the Economic Threshold Level (ETL). The performance of the proposed solution is judged in terms of the performance of the machine learning model and the accuracy of the proposed solution in the prediction of the stem borer attack on the sugarcane crop. The main objective of the proposed solution is to support sustainable developments in agriculture by using the IoT to capture the crop field context and machine learning to make data-driven decisions.
\end{abstract}

Keywords: Internet of things; machine learning; Naïve Bays; stem borer; sugarcane pest

\section{Introduction}

Agriculture is an important discipline for human life that guarantees the supply of necessities of life. Due to the increase in human population, the demand for food is increasing day by day and on the other side, agriculture is severely affected by global climatic changes [1]. One of the most adverse implications of the climatic changes is to enhance a pest attack on crops. With climatic changes, the pest attacks have decreased productivity in agriculture. Due to reduced productivity, agriculture is under pressure to produce more for an ever-increasing human population [2].

This work is licensed under a Creative Commons Attribution 4.0 International License, which permits unrestricted use, distribution, and reproduction in any medium, provided the original work is properly cited. 
Sugarcane is a major crop across the globe. In developing countries, it is a major cash crop that supports many industries. Brazil, India, Thailand, China, and Pakistan are major sugarcane growing countries. In 2018 sugarcane production has been 1.9 billion tons; Brazil at the top with 39\% of total production [3]. In 2018, sugarcane is grown at 26 Million hectares across the world. Sugarcane is grown for sugar production. Ethanol and biofuel are also obtained from sugarcane.

Pest attack is one of the major issues of the world crops. Sugarcane productivity is also severely affected by different types of borers and shoot borer is one of the major pest attacks on the sugarcane crop. The borer can cause 35 to $70 \%$ losses to the sugarcane crop [4]. There is an immense need for the use of modern technology to deal with the issue. Early predictions of the insect populations and their attack can be very useful for the effective control of the pest attack and to support other strategies of pest attack to be operative [5].

Pests are among the major reasons for the loss of agricultural productivity. Sugarcane is also heavily affected by pest attacks and borer attacks are one of the major issues of the sugarcane crop. Gurdaspur, top, stem, and root borers are the major pests of sugarcane [5]. Stem borer (Diatraea saccharalis, ) is a serious problem that can cause a loss of $30 \%-70 \%$ in sugarcane crop production [6]. A Sugarcane borer attacks young shoots especially from April to August when the temperature is high, coupled with low humidity in the selected area. The larvae make the 'dead heart structure that retards the growth at the point of infestation. The impacts of the sugarcane borer on the sugarcane crop are shown in Figs. 1 and 2.

The pest is found in Pakistan, India, the Philippines, Afghanistan, and Burma. The crop at the growth stage from one to three months is affected by the borer and is considered as the major problem of the early crop. Major symptoms are the dead heart and bores in the plant near the ground. The economic threshold level of the dead heart attack is $15 \%$ loss of the crop.

IoT is a new paradigm that is the integration of the sensors into the user environment with the use of the Internet as communication abilities [7,8]. IoT has shown many successful applications with the culture of smart cities, smart traffic management, smart homes, and smart patient care. With the advent of the IoT, the world is shaping into new forms with exciting applications.

IoT also has shown many successful applications in agriculture to develop precision agriculture and smart applications $[9,10]$. Internet of Things (IoT) has become the foundation technology for precision agriculture practices. Precision agriculture is the process to deal with crop field variations to use input according to the prevailing conditions .

Precision agriculture is to deal with inter and intra crop field variability and applications of inputs according to these variations [10]. Internet of Things (IoT) is an ideal technology to capture the variations in the crop field by deploying different types of sensing technologies. Climate-smart agriculture aims to improve agriculture productivity with changing global environmental conditions. Internet of Things (IoT) is also a strong candidate for the applications of climate-smart agriculture [11]. Global changes in environmental conditions have intensified the problem of pest attacks. An integrated approach is required to improve productivity in agriculture against the pest attack. An early prediction of the pest attack would be ideal for the integrated approach of pest attacks to be successful. Early warning and pest prediction would also be very helpful to apply the pest control strategy according to the predictions. This would decrease the cost of the use of insecticides that would ultimately decrease the cost of farmers and have a good impact on the environmental conditions by judicious use of the resources. The early predictions of pest attack would be a great advantage to support sustainable developments in agriculture and for the progressive use of precision and climate-smart agriculture [11].

There are many factors that influence the growth of the pest and insects. It is very hard to define the relationship between environmental conditions demands for data driven decisions using machine learning approach. 


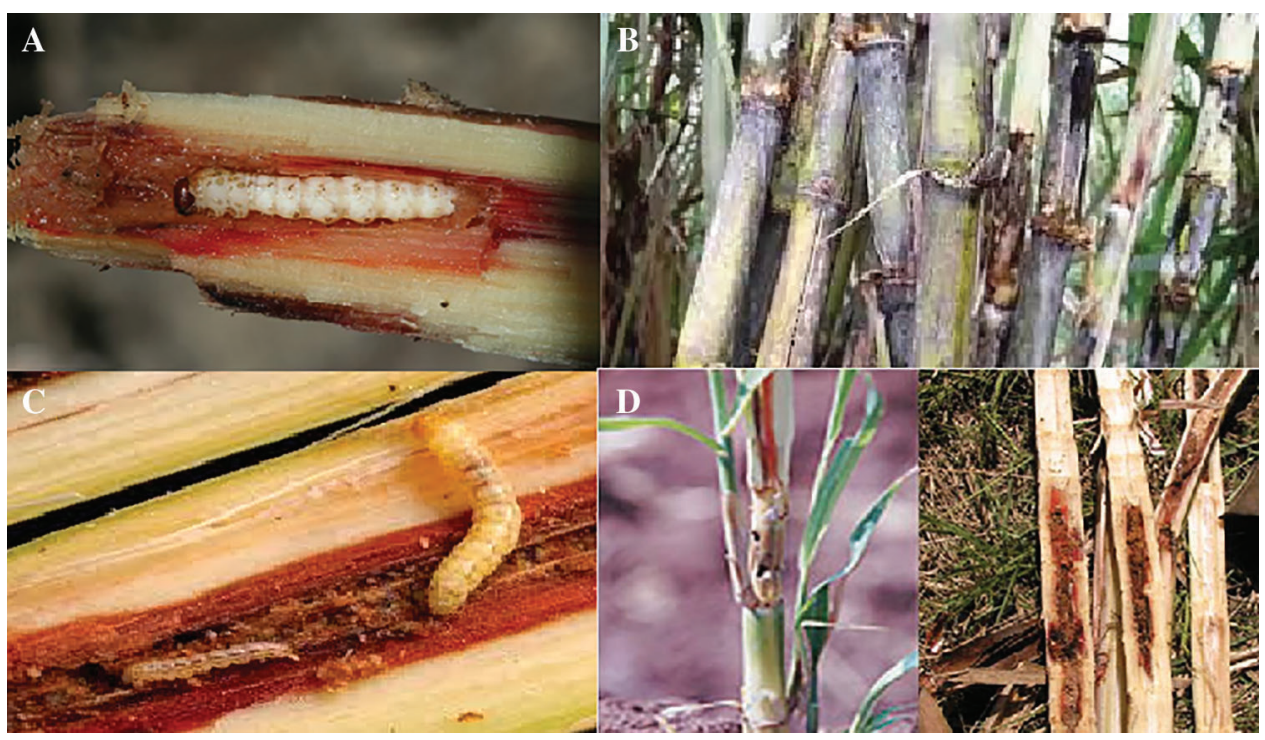

Figure 1: Impacts of sugarcane borer attack (A) Inner view after borer attack (B) Outer view after borer attack (C) Larva borer attack (D) Before and after borer attack view [4]

\subsection{Research Contribution}

This paper presents a novel model of sugarcane borer attack predictions to predict the population of the sugarcane borer on prevailing environmental conditions. The environmental conditions in these regards are temperature, humidity, and rainfall. The model is unique in the respect that it is designed to facilitate the implementation of IoT for real-time crop field monitoring and use of the machine learning capabilities on that dataset to decide the occurrence of borer attacks on sugarcane crops. The model is easily extendable for the other pests and other crops. The implementation of the model reveals that the model is accurate to predict the occurrence of borer attacks on sugarcane crops. The followings are the major contribution of the study.

- The study proposes a model of pest prediction based on directly sensed environmental conditions.

- The proposed model is unique in the sense that it considers multi parameters in predictions and uses the directly sensed environmental conditions.

\subsection{Organization of the Paper}

The remaining part of the paper is organized into the following three major sections. The related work presents the major findings and recent work for crop field monitoring, pest predictions, and machine learning applications. The material and method present the model of borer attack prediction, the IoT architecture for the proposed model, an implementation detail of the proposed solution. The environmental conditions sensed suing the proposed IoT architecture are also discussed. The results and discussion sections discuss the evaluation of the machine learning model and field evaluation of the proposed solution.

\section{Related Work}

Exciting applications emerged in recent years related to environmental monitoring, environment control, precision irrigation management, and many more. Major bibliographic indices are searched for various applications of IoT and machine learning applications in agriculture in general and pest prediction in specific. After a comprehensive review of the literature, the major findings of the literature reviews are given in this section. 

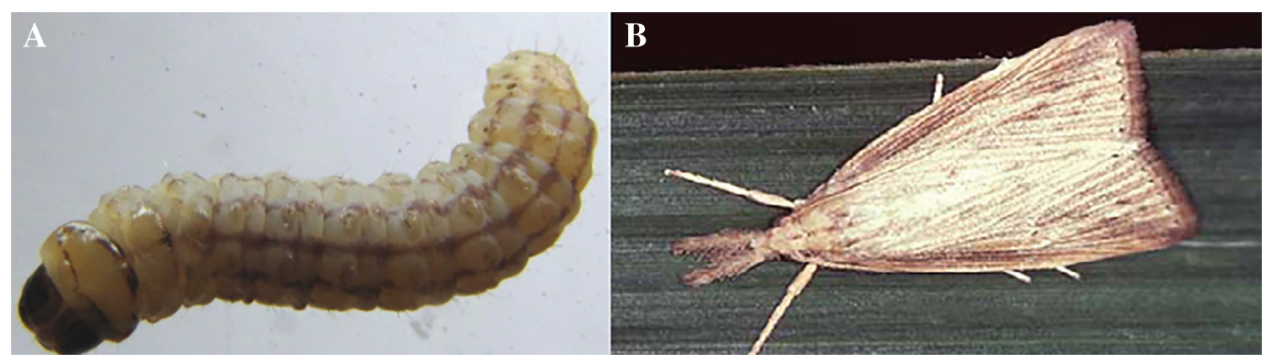

Figure 2: Larvae and adult of sugarcane borer (A) Larva borer (B) Adult Borer [4]

Many Site-specific input treatments are proposed while using the IoT capabilities. Lundström et al. [12] proposed site-specific applications of the inputs to conserve the inputs and efficient use of the resources. Ingo Pahlmann et al. [13] recommended site-specific use of the inputs especially the fertilizer. IoT assisted monitoring and Decision Support System has shown significant success. Abell et al. [14] proposed a farmers' Decision Support System (DSS) while using the IoT.

Liao et al. [15] also proposed the Internet of Things (IoT) monitoring of orchids. Uddin et al. [16] proposed a farmer decision support system using the Internet of Things (IoT) capabilities . Karim et al. [17] recommended IoT-based different types of applications emerged in recent years. Brewster et al. [18] explored the potential prospects of IoT and challenges of IoT in agriculture Ojha et al. [19] describe the potential applications of IoT in agriculture. Elijah et al. [20] explored prospects and challenges for the Internet of Things (IoT) in agriculture applications.

Internet of Things (IoT) applications deployment requires long-term standings and energy-efficient schemes. Jawad et al. [21] proposed an energy-efficient deployment of sensors for the Internet of Things (IoT) applications in agriculture. Talavera et al. [22] proposed automated control of equipment with the Internet of Things (IoT) and cloud computing.

Raghavendra et al. [23] identify the relationship between the pest and weather conditions on cotton crops. Liu et al. [24] proposed disease predictions based on environmental conditions using a neural network. Liu et al. [25] proposed tomato disease prediction based on the environment using the deep learning techniques from images of the tomato plants. Shang et al. [26] proposed an artificial neural network and Genetic Algorithm to predict the insect attack.

Yakkundimath et al. [27] proposed a plant health detection system. Ramesh et al. [28] recommended Internet of Things (IoT) based plant disease detection. Ayaz et al. [29] explored the possibilities of the Internet of Things (IoT) based solutions to deal with climate changes Kim et al. [30] proposed strawberry disease prediction from FAAS (Farm as a Service). Materne et al. [31] recommended Internet of Things (IoT) based environment monitoring for predictions of pest populations to deal with the issue of climate change impacts on the crop.

Sahu et al. [32] recommended pest detection using image processing. Okayasu et al. [33] proposed plant growth monitoring using the Internet of Things (IoT). Diedrichs et al., [34] developed frost predictions using temperature data to take necessary actions to prevent vineyards. Araby et al. [35] recommended an IoT-based pest warning system. Truong et al. [36] proposed fungal disease detection using the IoT and machine learning capabilities. Lee et al. [37] recommended weather-based diseased predictions using the Internet of Things (IoT) to reduce the use of pesticides. Syarif et al. [38] find the regression model and correlation between the pest population and weather conditions in corn crops. Bankar et al. [39] proposed plant disease prediction for early warning to prevent damage and take effective control measures. Villa-Henriksen et al. [40] explored the data-driven decision machine learning solution. 
Bashir et al. [41] proposed a IoT based approach to determine the amount of salinity and the end goal is to bring amount of salt to optimal level so that the fertility of soil can be ensured. Intelligent models use the temperature of crops and salinity level to predict amount of water that must leached. Cai et al. [42] recommended an Internet of Things-based greenhouse environment monitoring and crop field environment monitoring system. Weimin et al. [43] proposed automated intelligent greenhouse environment monitoring and control for the improvement in agriculture productivity.

Many exciting applications of the Internet of Things (IoT) and machine learning emerged in agriculture to promote precision agriculture practices. The most exciting applications are related to environmental monitoring, plant growth observations, irrigation water recommendations. Many solutions emerged to detect the disease and pest by image processing and machine learning to develop an early warning system. Some studies also identified the relationship between weather conditions and disease and pest predictions. Internet of Things (IoT) based environment monitoring and pest predictions based on environmental conditions is not suggested. The study uses the directly sensed crop field environment conditions for the pest attack prediction in sugarcane crops is never previously recommended.

\section{Materials and Methods}

The proposed solution is because the pest borer population grows well in high temperatures and low humidity. The borer attack on sugarcane increases with the increase of temperature and with the decrease of humidity. Rain also decreases the pest population due to the washout of the larva. Temperature, humidity, and rainfall are important parameters for the growth of pest populations. Therefore, these parameters are directly sensed from the crop field using the proposed architecture shown in Fig. 3. The sensed environmental data are transferred to the cloud using the gateway. The data from the cloud is fed into the machine learning model to make predictions. The predictions are conveyed to the end-users. The complete architecture is shown in Fig. 3.

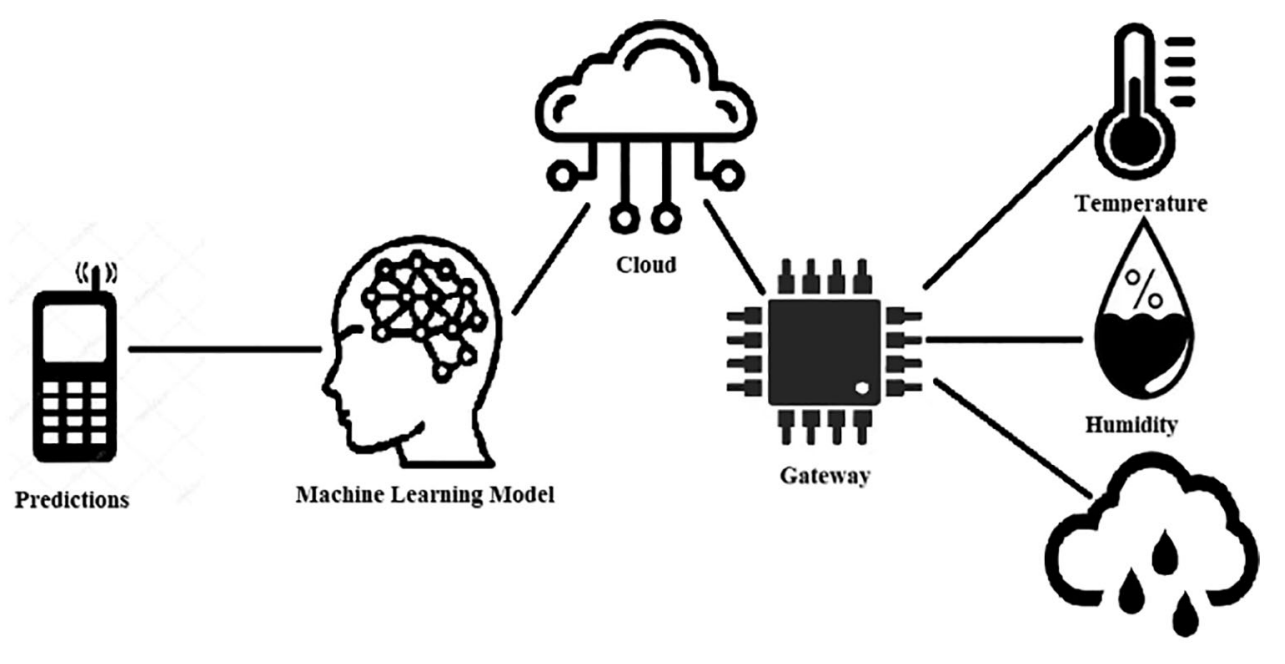

Rain Fall

Figure 3: Architecture of proposed solution

In the proposed architecture the environmental data from the sensor node is transferred to the server, through the gateway node. The directly sensed environmental parameters are used for the training and testing of the ML model, The directly sensed environmental conditions at the server are also used for making predictions. The prediction regarding the pest attack is conveyed to the end-users through the 
mobile application. The complete flow of environmental data and prediction made by the model is shown in Fig. 3.

The temperature and humidity are arranged into average weekly conditions to make weekly predictions. If the average weekly maximum temperature is above $35^{\circ} \mathrm{C}$ and humidity with less than $40 \%$, the predictions tend to be positive otherwise negative [4]. The rain washouts of the affected plants and maximum rainfall in the week are used to make predictions. If the maximum rainfall in the week is above $2.5 \mathrm{~mm}$, the chance of the attack is reduced. These correlations of the environmental conditions and pest populations are used to make predictions regarding the pest population is above or below the Economic Threshold Level (ETL). Average weekly temperature, average weekly humidity, and maximum rainfall are given by Eqs. (1)-(3).

Average Weekly Maximum Temperature $($ Tavg $)=\frac{\sum_{i=1}^{7} \text { Tmaxi }}{7}$

where "Tavg" is the average weekly maximum temperature, "Tmax" is the daily maximum temperature.

Average Weekly Maximum Humidity $($ Havg $)=\frac{\sum_{i=1}^{7} \text { Hmaxi }}{7}$

where "Havg" is the average maximum weekly humidity, "Hmax" is the daily maximum humidity.

Weekly Maximym Rainfall $($ Rmax $)=$ Max $_{R x i}$

where "Rmax" is the weekly maximum rainfall, "Rxi" is the daily maximum rainfall.

\subsection{Implementation Detail}

For implementation purposes, it is kept in mind that the cost of the solution should be minimum. DHT22 is used as a temperature and humidity sensor. It is a reliable sensor with an accuracy of 0.05 in temperature reading. A capacitive type of rain sensor is used. NodeMCU is used as a gateway node. The data from the sensor is transferred to the Firebase cloud using the NodeMCU gateway. These sensors and modules are shown in Fig. 4.

The hardware prototype is directly deployed in the field to sense the selected environmental conditions. The developed prototype is shown in Fig. 5.

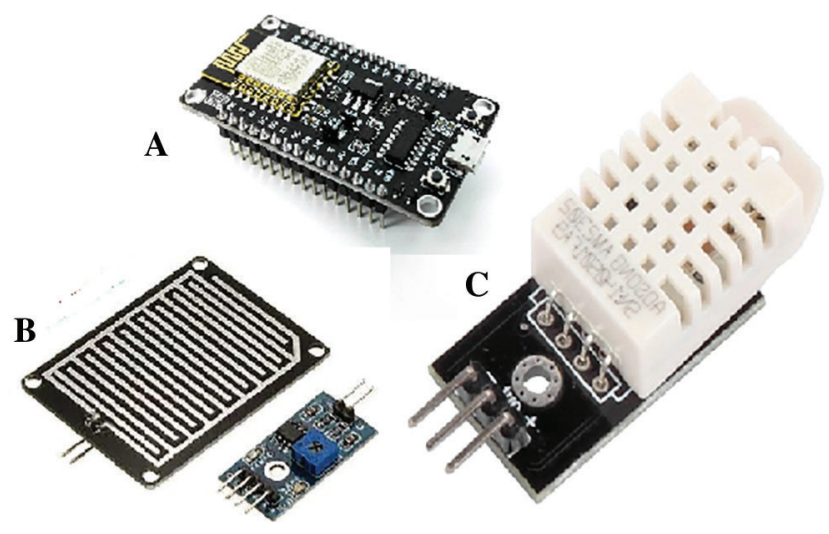

Figure 4: Gateway and sensors used for implementation (A) Node MCU (B) Rain Sensor (C) Temperature and humidity sensors 


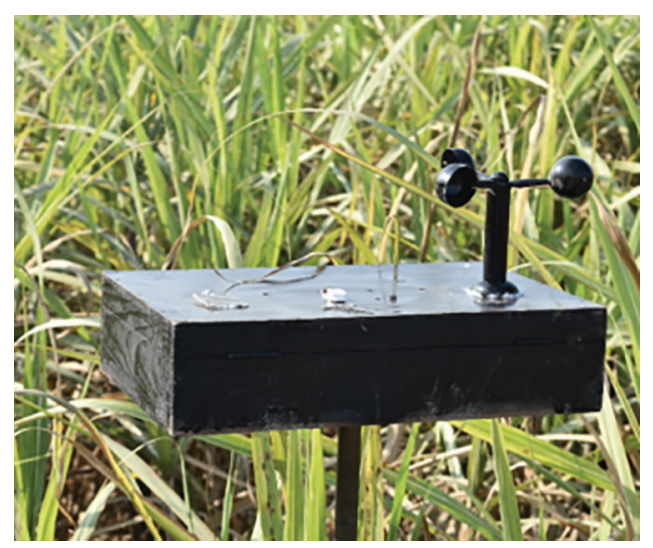

Figure 5: Hardware prototype in the field

\subsection{Machine Learning Model}

The relationship between the pest population and environmental conditions is diverse in nature and hard to define. This makes the problem hard and data-driven machine learning assisted decisions are proposed. Naïve Bayes is applied as a machine learning algorithm for a machine learning model of pest prediction. Naïve Bays is applied because of the following reasons.

- There exists an independence between the different parameters of pest growth like temperature, humidity, and rainfall.

- Naïve Bayes provide accuracy with small data set.

Naïve Bayes model is based on the Bays theorem of the conditional probability that the probability of an event is based on the already occurred event given by Eq. (4).

$P(t \mid S)=\frac{P(S \mid t) P(t)}{P(S)}$

where $t$ and $S$ are the events and $\mathrm{P}(\mathrm{t})$ is the probability of event $t, \mathrm{P}(\mathrm{S})$ is the probability of event $\mathrm{S}, \mathrm{P}(\mathrm{S} \mid \mathrm{t})$ is the evidence and $\mathrm{P}(\mathrm{t} \mid \mathrm{S})$ is the posterior probability given that evidence has occurred. The naïve Bayes model is selected for implementation purposes due to the following reason.

- It can show more accuracy with less data for the training dataset.

- Temperature, humidity, and rainfall have an independent impact on pest populations, and Naïve Bayes works best when data independence exists in predictor variables.

The naïve Bayes is a classification algorithm, and a set of weather conditions are used to predict the occurrence of a pest attack below, Intermediate, and below the Economic Threshold Level (ETL). The initial data set is partitioned into predictive feature matrices and response vector. Each vector of the predictive feature matrix is used to determine the value of the response vector. Each vector in the feature matrix has equal contribution and independence in the prediction of the pest attack. Due to the existence of independence in the predictive feature matrix, the Naïve Bayes theorem is applied to predict the value of the response vector. In case of a problem the " $\mathrm{t}$ " is a variable and $\mathrm{S}$ is the predictive feature vector of size ' $n$ ' where $S=\left\{s_{1}, s_{2}, \ldots s_{n}\right\}$. With each predictive vector $S=\{$ Temperature, Humidity, Rainfall $\}$, the value of pest attack (t) could be "Yes" or "No". For example, with the predictive feature matrix $\mathrm{S}=\{$ High, Low, Low $\}$ the $\mathrm{y}=\{$ Yes $\}$ means that the pest attack would be above the Economic Threshold Level (ETL) in case of high temperature, low humidity, and Low rainfall. The evidence is partitioned into 
independent classes by Eqs. (5)-(7).

$P\left(t \mid s_{1}, s_{2}, \ldots s_{n}\right)=\frac{P\left(s_{1} \mid t\right) P\left(s_{2} \mid t\right) \ldots P\left(S_{n} \mid t\right) P(t)}{P(S)}$

$P\left(t \mid s_{1}, s_{2}, \ldots s_{n}\right)=\frac{P(t) \prod_{i=1}^{n} P s_{i}}{P(S)}$

$y=\operatorname{argument}_{y} P(t) \prod_{i=1}^{n} P s_{i}$

The highest probability for "y" is taken by Eq. (7).

\subsection{Flow of the Proposed Solution}

The proposed solution is implemented based on flow chart as shown in Fig. 6. The daily environmental conditions are converted into mean weekly conditions. The mean weekly environmental conditions are provided to ML model as input. The ML model predicts the pest population above or below the threshold level. The predictions are fallowed by field observations to validate the predictions made by the model. The process is repeated on weekly basis the improve the performance of the model.

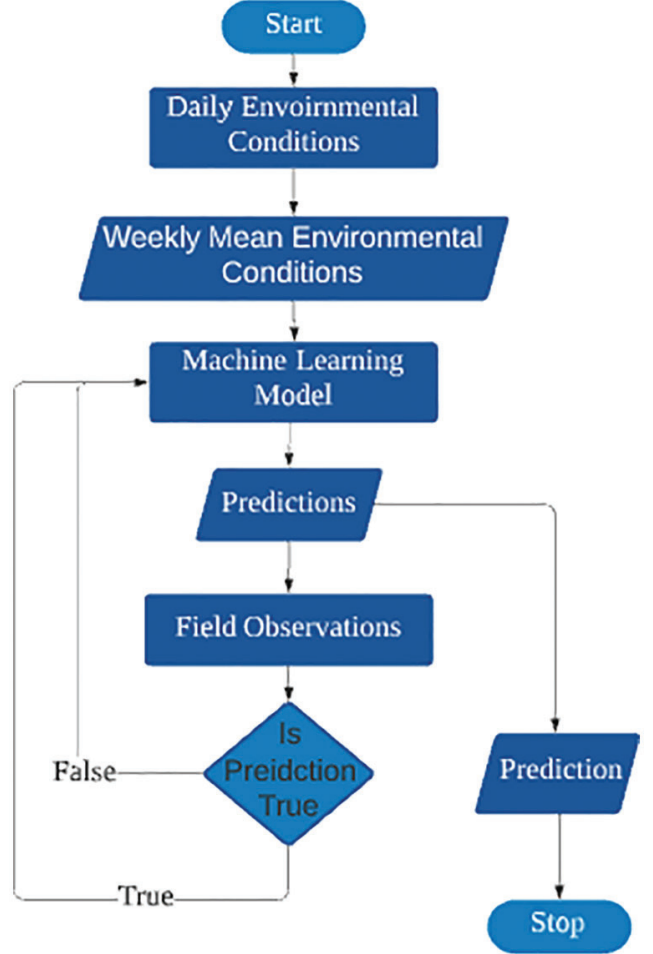

Figure 6: Flow chart of the proposed solution

\subsection{Classes of Environmental Conditions}

The proposed solution is implemented in district Vehari an intensive agriculture area in Pakistan. The solution is implemented on a commercial farm where sugarcane is grown. 
IASC, 2022, vol.31, no.3

The predictive feature classes are humidity, temperature, and rainfall shown in Tabs. 1-3 respectively, and the pest attack prediction classes are shown in Tab. 4 .

Table 1: Humidity classes

\begin{tabular}{ll}
\hline Humidity $(\%$ age $)$ & \\
\hline Low & $<40$ \\
Intermediate & $40-60$ \\
High & $>60$ \\
\hline
\end{tabular}

Table 2: Temperature classes

\begin{tabular}{ll}
\hline Temperature $\left({ }^{\circ} \mathrm{C}\right)$ & \\
\hline Low & $<30$ \\
Intermediate & $30-35$ \\
High & $>35$ \\
\hline
\end{tabular}

Table 3: Rainfall Classes

\begin{tabular}{ll}
\hline Rainfall $(\mathrm{mm})$ & \\
\hline Low & $<2.5$ \\
Intermediate & $2.5-7.6$ \\
High & $>7.6$ \\
\hline
\end{tabular}

Table 4: Pest prediction classes

\begin{tabular}{ll}
\hline Pest attack prediction (15\% crop) & \\
\hline Low & $<2.5$ \\
Intermediate & $2.5-7.6$ \\
High & $>7.6$ \\
\hline
\end{tabular}

The python sciket learn library is used for the development of a machine learning model. The input data is partitioned into training and test datasets in the ratio of 80:20. The yellow brick library of python is used for the evaluation of the machine learning model. 


\subsection{Environment Data Analysis}

Four-year data is used as the training set for the machine learning model. Temperature, humidity, and rainfall are the environmental conditions used to predict the borer population growth. The temperature, humidity, and rain fall are used as prediction data along with direct field observations to find the relationship between the environmental conditions and pest population. Daily maximum temperature and weekly average temperature from the year 2015 to 2019 are plotted in Fig. 7. Daily maximum humidity and weekly maximum humidity is plotted in Fig. 8. Daily maximum rainfalls and weekly maximum rainfall is plotted in Fig. 9. These environmental conditions are used to determine the pest population.

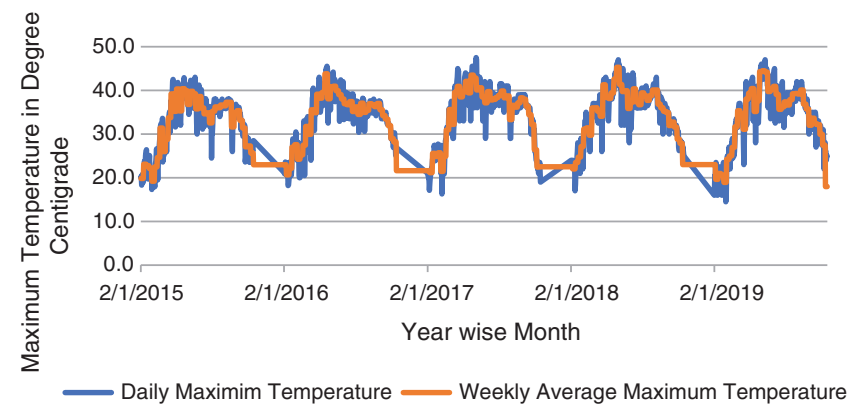

Figure 7: Temperature data analysis from 2015 to 2019

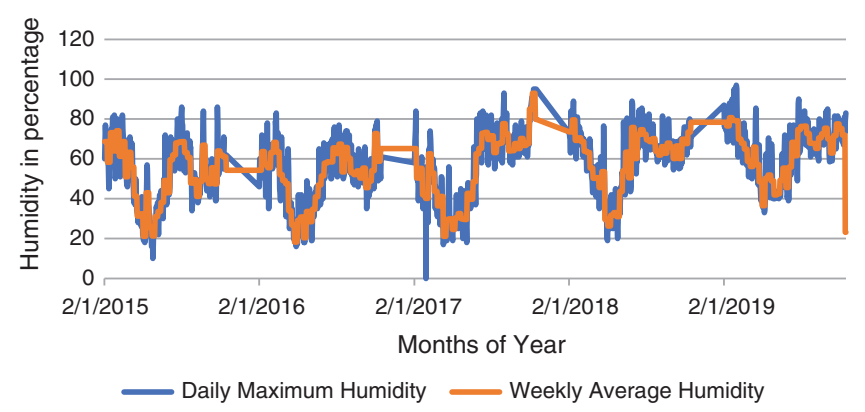

Figure 8: Humidity data analysis from 2015 to 2019

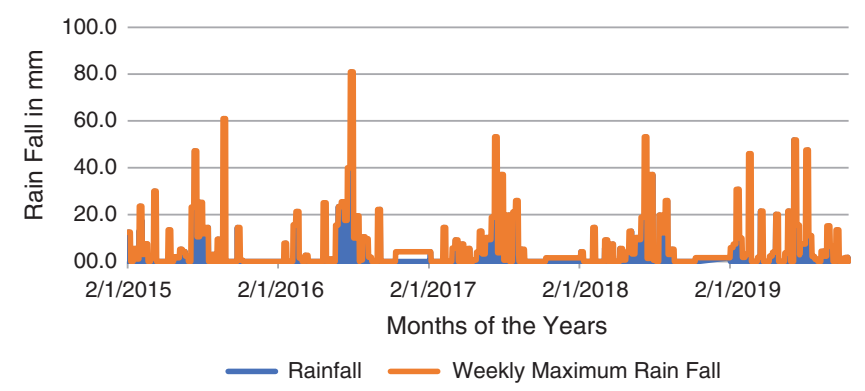

Figure 9: Rainfall data analysis from the year 2015 to 2019 
From Fig. 7, it is observed that April, May, June, July, and August are the hot months of each year. The temperature tends to decrease from September and decrease gradually in subsequent months.

From Fig. 8, it is observed that humidity is lower in the months when the temperature is high in the selected area. The humidity observation shows a similar pattern for all years.

From Fig. 9, it is observed that rainfall is lower in the months when the temperature is high in the selected area. From the environments, data is observed that April to June are the months when environmental conditions are favorable for the growth of the borer population. The stem borer grows very well in high temperatures with low humidity and minimum rainfall. These months have environmental conditions that are very favorable for the growth of the pest population.

\section{Result and Discussion}

The pest prediction model is evaluated by evaluation of the performance of machine learning model and accuracy of pest prediction by comparing against the field observations.

\subsection{Performance of Machine Learning Model}

The machine learning model is tested for its accuracy, precision, recall, and f-measure for its predictive features, and also tested from the test data set which is twenty percent of the total data. Precision is the number of positive predictions from a positive class and recall is the number of positive predictions from the total data set. F-measure balance the precision and recall measures. Accuracy is the number of correct predictions out of the total prediction made. The accuracy of the machine learning model is $83 \%$ when evaluated from the test data set. The precision-recall and $\mathrm{f}$-measure for the different predictive features are shown in the matrix in Fig. 10.

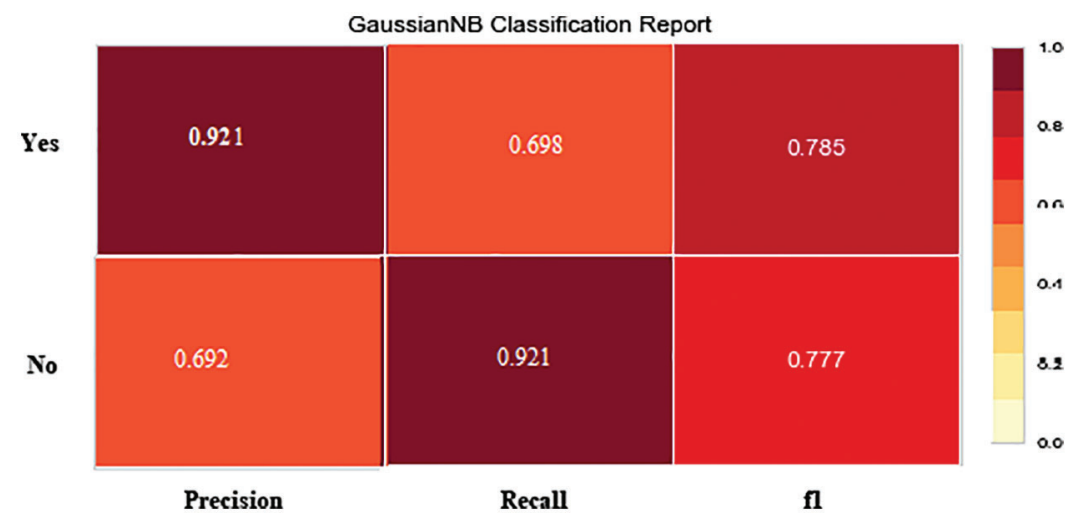

Figure 10: Performance matrix of the machine learning model

\subsection{Field Evaluation}

The pest detection using the proposed method is validated against the field observations. To observe the field eight acres are selected. In each acre, one hundred plants are observed for the attack of borer. If more than fifteen plants out of the observed plants are affected by the borer attack the crop is assumed to be affected, because the Economic Threshold Level (ETL) of the borer is $15 \%$ of dead hearts in sugarcane [44]. The field inspection is done on weekly basis. The field validation is made in the year 2018 and 2019. In each month four predictions are made. The accuracy of the prediction is checked against the field observations. In Fig. 11 the pest scouting is performed in the sugarcane crop. Figs.12 and 13 shows 
the borer attack percentage in the year 2018 and 2019. From Figs. 12 and 13, it is observed that borer attack tends to increase in hot months when humidity is also lower.

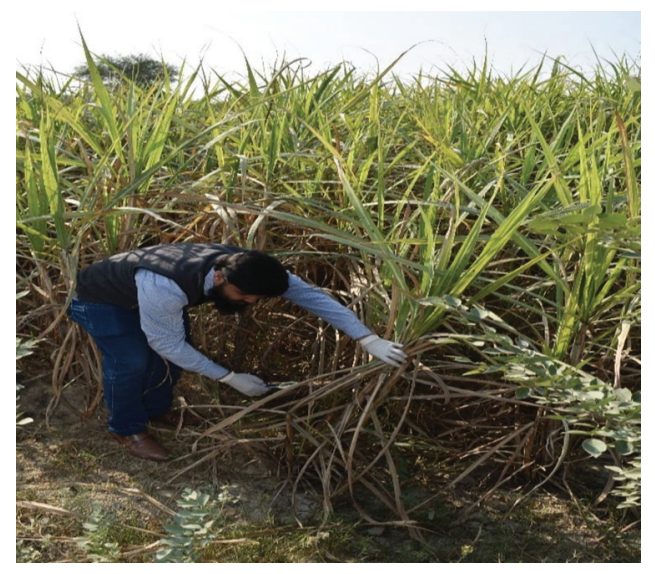

Figure 11: Pest scouting in the field

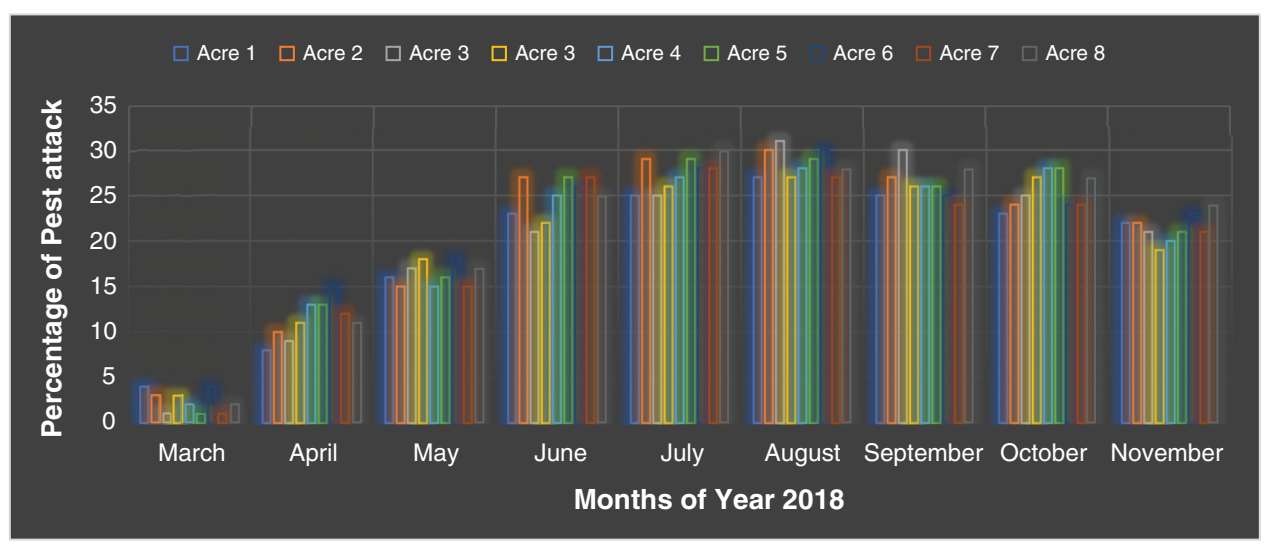

Figure 12: Percentage of cane affected by pest scouting methodology

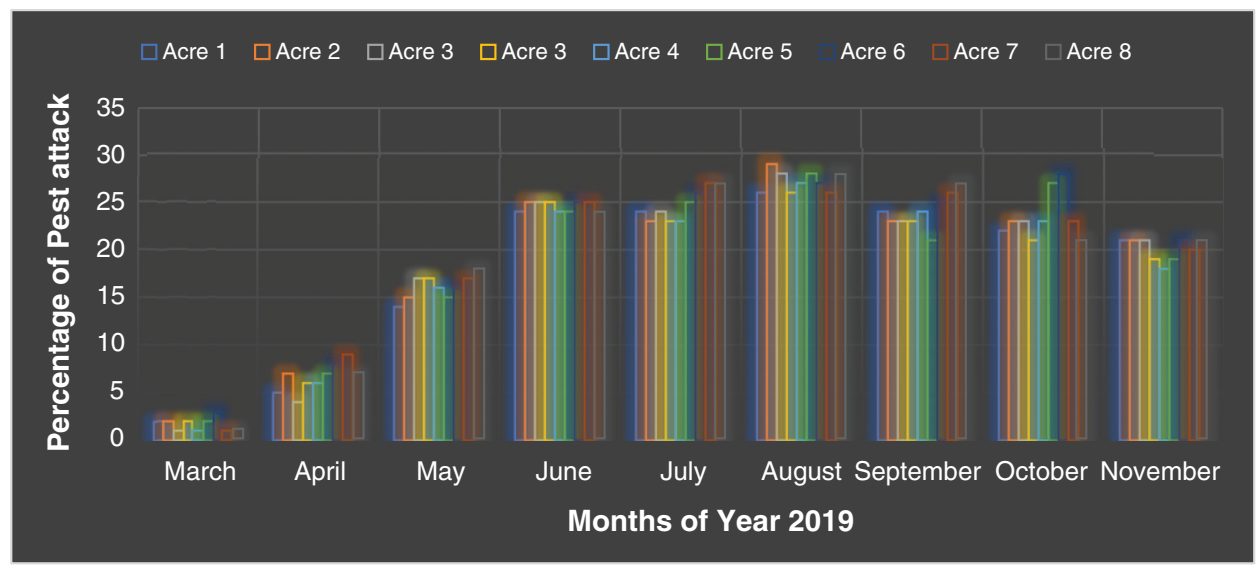

Figure 13: Percentage of cane affected by pest scouting methodology 
In each month four predictions are made one for each month. The number of correct predictions in the different months for the year 2018 and the year 2019, is shown in Fig. 14. In 2018 out of 36 predictions, 2 predictions are correct with $77 \%$ accuracy. In 2019 out of total 36 predictions 33 predictions are correct with $91 \%$ accuracy.

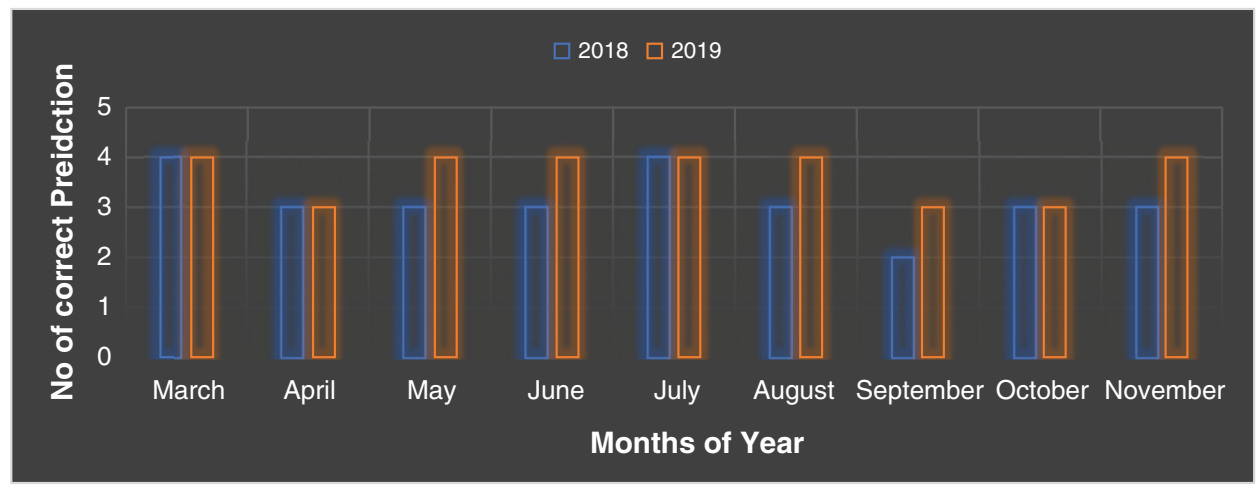

Figure 14: Correct Prediction in 2018 and 2019 for different months

\section{Conclusion}

IoT and machine learning based pest prediction is proposed, implemented, and evaluated. Internet of Things (IoT) helps to capture the real-time context of the crop field for the predictions of the pest population-based on temperature, humidity, and rainfall. The relationship between the borer population and environment conditions is used to make a data-driven machine learning model using the naïve bayes machine learning algorithm. The accuracy of the machine learning model is $83 \%$ when tested against the test data set. The proposed solution is also judged against the field evaluation by direct observation of the pest population. The predictions made by the proposed solution are compared against the actual pest population in the field. From the 2018 and 2019 observations, it is found that the proposed solution is $77 \%$ accurate in 2018 and $91 \%$ in 2019. Internet of Things (IoT) and machine learning-based pest prediction for stem borer is accurate to predict pest population. The proposed solution can be effectively used for Integrated Pest Management (IPM) to efficiently control pest attacks to support sustainable development in agriculture.

Apart from the environmental conditions many other field conditions also have influence on the growth of the pest. Use of the pesticides, presence of the predators and abundance pf the food are the important ones. While evaluations most care is taken that these conditions are similar but some variables are out of control to keep constant. This is also limitation of the study.

Acknowledgement: Dr. Arfan Jaffar, Rana M Nadeem and Rana M Saleem thanks to administration of University of Agriculture Faisalabad Sub Campus Burewala who allowed us to implement the solution in specific field for experiment purpose.

Funding Statement: The authors received no specific funding for this study.

Conflicts of Interest: The authors declare that they have no conflicts of interest to report regarding the present study. 


\section{References}

[1] M. Taylor, "Climate-smart agriculture: What is it good for?," The Journal of Peasant Studies, vol. 45, no. 1, pp. 89-107, 2018.

[2] FAO, "Global agriculture towards 2050," High Level Expert Forum-How Feed World, vol. 2050, pp. 1-4, 2009.

[3] C. B. Péné and Y. Coulibaly-Ouattara, "Sugarcane yields, juice quality and stem borer (Eldana saccharina W) infestations as influenced by increasing nitrogen rates in Ferké, Northern Ivory Coast," Journal of Agricultural and Crop Research, vol. 7, no. 5, pp. 72-81, 2019.

[4] S. A. Ali, N. Jan, M. Tahir and M. Ismail, Sugarcane entomology, 2016. [Online]. Available: https://www.scri. gkp.pk/EntomologySection.html.

[5] S. Nibouche, R. Tibere and L. Costet, "Erianthus arundinaceus as a trap crop for the sugarcane stem borer Chilo sacchariphagus: Field validation and disease risk assessment," Crop Protection, vol. 124, pp. 104877, 2019.

[6] A. Ogunsola, A. Zancaner and B. Seed, The Sugar Series: The Top 10 global Sugar Producers, 2021. [Online]. Available: https:/www.czarnikow.com/blog/the-sugar-series-the-top-10-sugar-producing-countries-in-the-world,

[7] K. A. M. Zeinab and S. A. A. Elmustafa, "Internet of things applications, challenges and related future technologies," World Scientific News, vol. 2, no. 66, pp. 126-148, 2017.

[8] K. Ashton, "That 'internet of things' thing," RFID Journal, vol. 22, no. 7, pp. 97-114, 2009.

[9] S. Rodríguez, T. Gualotuña and C. Grilo, "A system for the monitoring and predicting of data in precision agriculture in a rose greenhouse based on wireless sensor networks," Procedia Computer Science, vol. 121, no. 1, pp. 306-313, 2017.

[10] G. Aiello, I. Giovino, M. Vallone, P. Catania and A. Argento, "A decision support system based on multisensor data fusion for sustainable greenhouse management," Journal of Cleaner Production, vol. 172, no. 3, pp. 40574065, 2018.

[11] A. Chandra, K. E. McNamara and P. Dargusch, "Climate-smart agriculture: Perspectives and framings," Climate Policy, vol. 18, no. 4, pp. 526-541, 2018.

[12] C. Lundström and J. Lindblom, "Considering farmers' situated knowledge of using agricultural decision support systems (AgriDSS) to foster farming practices: The case of CropSAT," Agricultural Systems, vol. 159, no. 1, pp. 9-20, 2018.

[13] I. Pahlmann, U. Böttcher and H. Kage, "Developing and testing an algorithm for site-specific N fertilization of winter oilseed rape," Computers and Electronics in Agriculture, vol. 136, no. 3, pp. 228-237, 2017.

[14] K. M. Abell, M. E. Theurer, R. L. Larson, B. J. White, D. K. Hardin et al., "Predicting bull behavior events in a multiple-sire pasture with video analysis, accelerometers, and classification algorithms," Computers and Electronics in Agriculture, vol. 136, pp. 221-227, 2017.

[15] M.-S. Liao, S.-F. Chen, C.-Y. Chou, H.-Y. Chen, S.-H. Yeh et al., "On precisely relating the growth of Phalaenopsis leaves to greenhouse environmental factors by using an IoT-based monitoring system," Computers and Electronics in Agriculture, vol. 136, pp. 125-139, 2017.

[16] M. A. Uddin, A. Mansour, D. Le Jeune and E. H. M. Aggoune, "Agriculture internet of things: AG-IoT," in 2017 27th Int. Telecommunication Networks and Applications Conf., Melbourne, VIC, Austraila, pp. 1-6, 2017.

[17] F. Karim and F. Karim, "Monitoring system using web of things in precision agriculture," Procedia Computer Science, vol. 110, pp. 402-409, 2017.

[18] C. Brewster, I. Roussaki, N. Kalatzis, K. Doolin and K. Ellis, "IoT in agriculture: Designing a Europe-wide largescale pilot," IEEE Communications Magazine, vol. 55, no. 9, pp. 26-33, 2017.

[19] T. Ojha, S. Misra and N. S. Raghuwanshi, "Sensing-cloud: Leveraging the benefits for agricultural applications," Computers and Electronics in Agriculture, vol. 135, no. February, pp. 96-107, 2017.

[20] O. Elijah, T. A. Rahman, I. Orikumhi, C. Y. Leow and M. N. Hindia, "An overview of internet of things (IoT) and data analytics in agriculture: Benefits and challenges," IEEE Internet of Things Journal, vol. 5, no. 5, pp. 37583773, 2018.

[21] H. M. Jawad, R. Nordin, S. K. Gharghan, A. M. Jawad and M. Ismail, "Energy-efficient wireless sensor networks for precision agriculture: A review," Sensors, vol. 17, no. 8, pp. 1781, 2017. 
[22] J. M. Talavera, L. E. Tobón, J. A. Gómez, M. A. Culman, J. M. Aranda et al., "Review of IoT applications in agroindustrial and environmental fields," Computers and Electronics in Agriculture, vol. 142, pp. 283-297, 2017.

[23] K. Raghavendra, D. B. Naik, S. Venkatramaphanikumar, S. D. Kumar and S. R. Krishna, "Weather based prediction of pests in cotton," in 2014 Int. Conf. on Computational Intelligence and Communication Networks, Bhopal, India, pp. 570-574, 2014.

[24] G. Liu, H. Shen, X. Yang and Y. Ge, "Research on prediction about fruit tree diseases and insect pests based on neural network," in IFIP Int. Conf. on Artificial Intelligence Applications and Innovations, Lauderdale, FL, USA, pp. 731-740, 2005.

[25] J. Liu and X. Wang, "Tomato diseases and pests detection based on improved Yolo V3 convolutional neural network," Frontiers in Plant Science, vol. 11, pp. 898, 2020.

[26] Y. Shang and Y. Zhu, "Research on intelligent pest prediction of based on improved artificial neural network," in 2018 Chinese Automation Congress, Xian, China, pp. 3633-3638, 2018.

[27] R. Yakkundimath, G. Saunshi and V. Kamatar, "Plant disease detection using IoT," International Journal of Engineering Dcience and Computing, vol. 8, pp. 18902-18906, 2018.

[28] S. Ramesh and D. Vydeki, "Application of machine learning in detection of blast disease in south Indian rice crops," Journal of Pathology, vol. 11, pp. 31-37, 2019.

[29] M. Ayaz, M. Ammad-Uddin, Z. Sharif, A. Mansour and E.-H. M. Aggoune, "Internet-of-things (IoT)-based smart agriculture: Toward making the fields talk," IEEE Access, vol. 7, pp. 129551-129583, 2019.

[30] S. Kim, M. Lee and C. Shin, "IoT-based strawberry disease prediction system for smart farming," Sensors, vol. 18, no. 11 , pp. $4051,2018$.

[31] N. Materne and M. Inoue, "Iot monitoring system for early detection of agricultural pests and diseases," in 2018 12th South East Asian Technical University Consortium, Yogyakarta, Indonesia, pp. 1-5, 2018.

[32] C. K. Sahu, P. K. Sethy and S. K. Behera, "Sensing technology for detecting insects in a paddy crop field using optical sensor," in Information and Communication Technology for Sustainable Development. Berlin, Germany: Springer, pp. 191-199, 2018.

[33] T. Okayasu, A. P. Nugroho, A. Sakai, D. Arita, T. Yoshinaga et al., "Affordable field environmental monitoring and plant growth measurement system for smart agriculture," in 2017 Eleventh Int. Conf. on Sensing Technology, Sydney, NSW, Austraila, pp. 1-4, 2017.

[34] A. L. Diedrichs, F. Bromberg, D. Dujovne, K. Brun-Laguna and T. Watteyne, "Prediction of frost events using machine learning and IoT sensing devices," IEEE Internet of Things Journal, vol. 5, no. 6, pp. 4589-4597, 2018.

[35] A. A. Araby, M. M. Abd Elhameed, N. M. Magdy, N. Abdelaal, Y. T. Abd Allah et al., "Smart IoT monitoring system for agriculture with predictive analysis," in 2019 8th Int. Conf. on Modern Circuits and Systems Technologies, Thessaloniki, Greece, pp. 1-4, 2019.

[36] T. Truong, A. Dinh and K. Wahid, "An IoT environmental data collection system for fungal detection in crop fields," in 2017 IEEE 30th Canadian Conf. on Electrical and Computer Engineering, Windsor, ON, Canada, pp. 1-4, 2017.

[37] H. Lee, A. Moon, K. Moon and Y. Lee, "Disease and pest prediction IoT system in orchard: A preliminary study," in 2017 Ninth Int. Conf. on Ubiquitous and Future Networks, Milan, Italy, pp. 525-527, 2017.

[38] I. Syarif, D. H. Indiarto, I. Prasetyaningrum, T. Badriyah and E. Satriyanto, "Corn pests and diseases prediction using linear regression and natural spline methods," in 2018 Int. Conf. on Applied Science and Technology, Manado, Indonesia, pp. 383-387, 2018.

[39] S. Bankar, A. Dube, P. Kadam and S. Deokule, "Plant disease detection techniques using canny edge detection \& color histogram in image processing," International Journal of Computer Science and Information Technology, vol. 5, pp. 1165-1168, 2014.

[40] A. Villa-Henriksen, G. T. Edwards, L. A. Pesonen, O. Green and C. A. G. Sørensen, "Internet of things in arable farming: Implementation, applications, challenges and potential," Biosystems Engineering, vol. 191, no. 6, pp. 60-84, 2020.

[41] R. N. Bashir, I. S. Bajwa and M. M. A. Shahid, "Internet of things and machine-learning-based leaching requirements estimation for saline soils," IEEE Internet of Things Journal, vol. 5, pp. 4464-4472, 2019. 
[42] C. Cai, L. Hui and H. Wenjun, "Internet of agriculture-based low cost smart greenhouse remote monitor system," IEEE Chinese Automation Congress, pp. 3940-3945, 2018.

[43] Q. Weimin, L. Dong, F. Wang and H. Yan, "Design of intelligent greenhouse environment monitoring system based on ZigBee and embedded technology," in IEEE Int. Conf. on Consumer Electronics, China, pp. 1-3, 2014.

[44] R. Venkatachalam and K. Ilamurdgn, Pest of sugarcane, 2009 [Online]. Available: http://eagri.org/eagri50/ ENTO331/lecture12/001.html. 